\title{
BALBUCEO LITURGICO EN EL CAMINO DEL MIGRANTE. ENSAYO SOBRE LAS EXPRESIONES -GESTOS- RITUALES DEL PUEBLO INDOCUMENTADO Y REFUGIADO DESDE CENTRO AMÉRICA HACIA EL NORTE
}

P. FLOR MARIA RIGONI, C.S. *

INTRODUCCIÓN

A ndando por las veredas de la migración, sentado en la misma mesa con los indocumentados y con cuantos son hijos del viento y de nadie, en las Casas Scalabrini del Migrante, en los campamentos de refugiados o asomándome al mundo de los solicitantes de refugio, he intentado ser sus oídos, ojos y su corazón. Compartiendo con ellos esperanzas, dramas y lágrimas, el dolor del fracaso y de la exclusión, el sueño por una patria que les proporcione pan; me hallé muchas veces celebrando una liturgia sin reglas, donde las rúbricas nacían de los relatos de esta gente en camino. Eran celebraciones a veces calladas, donde el llanto era la música de trasfondo de un misterio que nos rebasaba a todos; otras veces las lágrimas de mamás o jóvenes, aplastadas por la hambruna o heridas profundamente en su dignidad

\footnotetext{
* El padre Flor María Rigoni es Misionero de San Carlos Scalabrini, orden que en 1985 tuvo la iniciativa de abrir la primera Casa del Migrante Scalabrini, en Tijuana B.C. y desde esa fecha ha venido abriendo albergues similares en Ciudad Juárez en Chihuahua, Tecún Umán en Guatemala, Tapachula en Chiapas, Ciudad de Guatemala y Agua Prieta en Sonora.

Estos lugares son centros de hospitalidad para todo tipo de migrantes donde se brinda alojamiento, comida, primera atención médica, información sobre derechos humanos, entre otros, con el afán de hacer menos escabroso el andar de los migrantes por tierras extrañas. Todo en conjunto con otras ONG's, iglesias y con donativos de diferentes fuentes.

El padre Rigoni es actualmente el Director de la Casa de Tapachula en Chiapas (http:// www.migrante.com.mx/Tapachula.htm) que tiene lugar para 45 personas, generalmente centroamericanos, y protege a los migrantes de abusos de las autoridades, de bandidos y les brinda ayuda en las necesidades básicas de alimento, salud y descanso. De su experiencia en esta Casa, creada en 1997, aunada a vivencias anteriores se deriva el siguiente trabajo.
} 
por la corrupción o el estupro, se volvían agua para un bautismo de novedad o rito de bendición.

En las diferentes etapas de mi vida misionera iba empapándome de un mensaje que tenía un hilo conductor común y al mismo tiempo los matices específicos de unas etnias, de un momento histórico distinto y las temáticas del dolor y de la alabanza se correteaban en la hilada del discurso o de la pausa celebrativa. Era toda una serie de tradiciones, que venían pasándose de boca en boca, de memoria en memoria, hasta parecerse a los primeros núcleos de los evangelios, marcados con fuego por las comunidades primitivas. En mi experiencia con los migrantes, más que de evangelio pienso sea más correcto hablar de un corpus liturgicus informal, un cúmulo de expresiones, que he intentado recopilar, ordenar e interpretar en un plan teológico y eclesial.

La seducción de mi ser misionero para con los migrantes, hijo de Scalabrini e hijo de una iglesia peregrina ha sido el contagio por el Dios del camino, por este Yahwé que se revela al andar. En este caminar con los hermanos y hermanas migrantes, chocando con muros y fronteras, con discriminación y rechazo, he llegado a un umbral nuevo de mi vida.

Contemplo un horizonte mojado de la sencillez de los pobres, embriagado por la audacia de quien avienta el corazón más allá de fronteras y pasa por encima de púas o cruza campos minados. Es un nuevo amanecer cargado de esperanza y liberación.

En la experiencia del destierro, en nuestras tiendas plantadas a veces en tierra quemada por la aplicación de una ley sin alma o por el acoso codificado y sellado por la impunidad, me siento impulsado a dar voz y rostros a esta humanidad migrante despojada de nombre, derechos y rasgos $^{1}$ y sin embargo tienda del Emmanuel, susurro de novedad de un Dios que sigue naciendo allí afuera, en los diferentes establos de las Belén de nuestro tiempo.

\section{TIPOLOGÍA DEL MIGRANTE}

\section{El indocumentado}

El indocumentado es el nuevo migrante de nuestros días. Llega al cruce de un estado con otro, rico tan solo de su esperanza. Su pasaporte es el corazón abierto de quien lo acoge. No tiene nombre ni identidad: hoy se llama Pedro, mañana Paco... su proveniencia puede ser Honduras, Guatemala, Salvador o Nicaragua, México o Colombia. Se disfraza conforme la necesidad. No tiene nada que perder: ya metió su vida en una baraja sin límites. Todo su haber está recogido en una mochila o en la bolsa de plástico de la última tienda donde compró dos tacos. A veces toda su patria y su cultura se expresan en el

\footnotetext{
1 Véase El Clamor de los indocumentados, Mensaje de la Red Casas del Migrante Scalabrini, Miércoles de Ceniza de año jubilar 2000.
} 
«descamisado» que cruza como quien se mete a bañar.

El indocumentado es hijo de nadie, no cuenta ni tiene voz: ni por su tierra que lo despidió: callada, indiferente, tal vez con gozo o a patadas. Es nadie para la tierra que se abre a su vista, tan sólo para estadísticas o por aquel juego feroz y contradictorio que es la explotación de su trabajo.

Existe el indocumentado que simplemente es fruto de aquel proceso de persuasión oculta y masiva de la publicidad, que lo ha venido convenciendo de que todo lo bueno está solamente en el Norte. Proceso boomerang que ve al tercer mundo en marcha hacia la conquista de un El Dorado, que el mundo occidental vendió de remate y que ahora quiere defender a uñas y dientes. Hay perseguidos políticos, a quienes se les considera enemigos, terroristas ideológicos tan sólo porque están al otro lado de la barricada. Hay gente que huye de su tierra, porque ya no sabe más donde ubicarse, víctima de una zamba de revoluciones y contrarrevoluciones, de contradicción y confusión ideológica. Hoy en día cada vez es más grande la distinción entre indocumentado, o migrante económico, como se le dice en lenguaje técnico, y refugiado.

En Centro América, por ejemplo, por la criminalidad generalizada sobre todo el territorio, por una falta de sistema judicial confiable, por la autoridad corrupta, podemos hablar de una guerra civil no declarada, donde mucha gente ya huye por sobrevivencia. Los sociólogos y Naciones Unidas definen el nuevo fenómeno como flujo migratorio mixto.

\section{El refugiado}

El refugiado es el último de los pobres: no goza de derecho alguno, ya sea en su propia tierra, con los de su patria; a lo largo de su peregrinación que hace de su éxodo desierto y calvario al mismo tiempo. Se lleva marcado con fuego en su carne el estigma de ser revolucionario, potencial criminal, «otro», de otra etnia, de otro credo o ideología.

A veces, cuando el refugiado ha finalizado su camino de ilusiones en la nueva tierra, empieza para él la búsqueda de una nueva dimensión entre pasado y futuro, entre sus raíces y la necesidad de ser otro en otra tierra. Siente muchas veces ser vigilado hasta dentro de fronteras seguras que le han abierto las puertas. Es extranjero dos veces, porque lleva algo que lo confinó de su propia patria.

Mientras para el indocumentado brincarse afuera o al norte significa el camino de un solo sentido hacia una nueva ilusión de riqueza o de mejoría, el refugiado es una brújula abierta a los 4 vientos: su destino puede ser tanto el norte como el sur, el este o el oeste; la acogida o la deportación. Él hizo ya tierra quemada a su alrededor y se presenta como el hambriento que te agradece cualquier migaja. 
El refugiado es un indocumentado perseguido y desterrado. Sale de su tierra sin siquiera poderse acurrucar en la nostalgia de regresar: las fronteras se cierran a su espalda en una mezcla de sentimientos que van desde la euforia, el fracaso y hasta la duda, cuando no se torna remordimiento por haber traicionado a una madre. El refugiado, como el indocumentado, acaba seguido por huir de sí mismo y el drama termina en la alienación de todo un pueblo.

La liberación empieza con la despedida del lugar de la opresión, sacudiéndose instituciones y recuerdos y sin embargo los lleva a lo largo del camino de éxodo. Vive el complejo de ser víctima, de ser un caso especial y termina muchas veces en volverse exigente, crítico violento de la nueva sociedad, firme en la creencia de que todo se le debe. Termina enajenado consigo mismo, con la vecindad y con su tierra de origen. La necesidad de justificar su salida, la pregunta callada y profunda que a quemarropa le echa en cara de ser un cobarde, porque abandonó la lucha, sus seres queridos o sus compañeros, de credo o de ideología, lo empujan hacia una esquizofrenia maniática.

El refugiado es así víctima de un juego que él quizá no entiende. Es alguien que no cabe en el mosaico de las nuevas categorías; un marginado violado, cuando no acepta serlo voluntariamente. Es el último anillo de una cadena de desecho que degolla toda cumbre, allana toda diversidad. Es el patito feo de la nueva orden: todos se arrogan el derecho de rechazarlo, ignorarlo o perseguirlo.

\section{El desplazado}

Lo podemos llamar el «desterrado» en su patria. Es víctima de «razones mayores» o de la así llamada «seguridad nacional». Me refiero, por mi experiencia, fundamentalmente a situaciones de guerra civil. Sin embargo en las catástrofes naturales, cuando las condiciones de paracaidista se prolongan, las condiciones no son muy diferentes de lo que pasa en una guerra civil o ideológica.

Tiene que moverse desarraigándose de su ambiente vital, de una libertad que el mismo marcaba, para desplazarse en zonas que más bien se parecen a campos de concentración por el control militar o gubernamental que se ejerce. El desplazado ni siquiera tiene el gusto de poder voltearse para atrás y echar una ojeada sobre lo que había sido el terreno de su esclavitud. Su drama se consuma en su tierra, en una herida que sigue sangrando, vertiente de enfrentamientos que hacen de él una víctima impotente y ajena.

\section{Elementos comunes}

La misma solidaridad de los pobres ha sido quebrantada. El largo camino del refugiado o del indocumentado se ha transformado en una lucha solitaria, sendero de la jungla con todas sus dudas y peligros. Es el resultado de una guerra entre pobres, donde cada quien quiere salir ganando a costa de lo que sea. Centro América es la más pequeña de este Continente y sin 
embargo es teatro de un juego que supera su tamaño. Es el ajedrez de un choque ideológico y político que viene de lejos, cuña estratégica donde los grandes bloques se están desafiando en un enfrentamiento de gigantes. Los entrenamientos militares se han vuelto guerra, donde los blancos ya son pueblos enteros y la simulación realidad.

Su silencio pone de manifiesto la otra parte callada, la que no cuenta, la que no se conforma y que tal vez es lugar de la profecía de una verdad, que empieza en nuestra historia y finaliza más allá del tiempo y de nuestras políticas. Es el silencio de cuantos tienen que salirse callados, bajo la percepción de que salen sobrando, que pocos llorarán su despedida, fuera de sus familiares. Al comienzo es la experiencia de ser unos derrotados.

Esta migración es signo de nuestro tiempo, cumbre de un iceberg que queda hundido en la realidad diaria de nuestro pueblo latinoamericano. El migrante de todo tipo es expresión de un tercer mundo sin derechos y sin voz en el ajedrez de los grandes poderes políticos y económicos. Él no tiene un lugar propio de autonomía, en nuestra América latina ha desaparecido desde hace tiempo la libertad de una política y cultura propia, arraigada en la sabiduría de nuestra historia y tradición popular: hay que optar por la ideología capitalista o marxista, o según una expresión de Cantinflas, entre verdes $y$ colorados.

Ir hambrientos y sedientos, después de haber tomado la decisión de salir, sobre un camino que van abriéndose con la oración, aventando la esperanza hacia el cielo, es el contexto clásico de muchos migrantes indocumentados, de los deportados y hasta de unos refugiados. Hoy en día se nos hace difícil pensar en una liturgia afuera de todo un ritual marcado por las rúbricas, los textos codificados por la iglesia, los rituales definidos. En mi experiencia unos tatuajes de los migrantes con la Virgen de Guadalupe o de un ángel quieren sellar la protección y la devoción a través de este método moderno, si queremos llamarle así. ${ }^{2}$ El migrante puede tener su lugar por derecho dentro de la expresividad religiosa del pueblo de Dios y de un pueblo peregrino.

\section{RELIGIOSIDAD DE MÉXICO, CENTRO AMÉRICA Y EL MIGRANTE}

La religiosidad es, sin duda, uno de los principales elementos de la identidad mexicana. Si hablamos de la estructuración violenta que se vino perfilando desde la colonización de México, la religión fue a la vez la justificación de esa violencia y el antídoto contra ella. Los símbolos de la mexicanidad tienen su origen en la

\footnotetext{
2 Vale la pena aquí distanciarnos de una moda que está entrando en los miembros de las Pandillas, por ej. los Maras Salvatruchas, de tatuarse con la Virgen o símbolos religiosos, por una superstición que quiere alejar las balas de los contrincantes. Así tendríamos que analizar unos rituales esotéricos, a veces satánicos para derrotar a los demás.
} 
religión y los propios héroes históricos son revestidos de una fuerte carga de religiosidad.

Los pueblos indígenas latinoamericanos tenían un profundo sentido de lo sagrado. El núcleo de la evangelización, sin aprobar por supuesto los elementos de imposición y a veces de violencia, fue transferir y conciliar los elementos sagrados de la religión prehispánica con el credo y la simbología cristiana. El Indígena en su contacto con los primeros misioneros partía de una experiencia natural, profundamente arraigada con sus dioses y diosas. La vida cotidiana del indígena era esencialmente religiosa: con la conquista se vuelve cristiana. $^{3}$

Este testimonio de un campesino de Honduras, sobreviviente del Huracán Mitch, es uno de los marcos referenciales que preceden y celebran el momento de la despedida. Es una cita que viene desde lejos, meditada, soñada y de repente cancelada como pesadilla. Regresa de puntillas delante de bocas que piden pan, mientras el café ya no tenía precio y el gorgojo se había llevado la cosecha $a^{4}$ se parece a la noche del pueblo de Dios con el cayado en la mano y un pie sobre el umbral de salida del hogar.

«Todo se lo había llevado el río. Hasta los muertos. Me dijo mi madre: hijo, vende esta vieja radio, sácate un puñado de Lempiras y vete al Norte... » esto me decía, como para darle rostro a la esperanza. Me despidió, imponiéndome las manos y bendiciéndome. Un nudo a la garganta enlazaba a los dos: acababa de perder a mi mujer y tres niños, ahora era como enterrar viva a mi madre.

Me quedaba mi sudor de pobre, era ya mi llanto callado. ${ }^{5}$

La constatación es amarga. Es la última estación del tren de la vida de alguien, que está colgado sobre el acantilado. Todo lo ha intentado y todo al mismo tiempo se le ha venido abajo; la soledad, las noches de luna o de tormenta han secado este escurrir de lágrimas escondido a los demás. La figura de la madre en la despedida asume una vivencia única. El drama alcanza su vértigo. El olvidarse de su madre es olvidarse de que Dios existe. ${ }^{6}$

Por un lado, todo hijo quisiera quedarse al lado de su madre, por el otro sufre su miseria, la de aquella mujer encorvada bajo el tercio de leña, torteada ella misma por el fogón de las tortillas o de las popusas; es la gota que hace derramar el vaso: Me decía: ya vengo, voy a buscar el pan de cada día; salía solamente con un "Sol» (la moneda de mi país). Luego regresaba con el canasto con arroz y pescado. Yo le preguntaba: iComo le hiciste, ma?... Ella me respondia: Dios se lo da a quien no tiene.?

\footnotetext{
${ }^{3}$ Alessandrini, c.s. Manuscriptum.

${ }^{4}$ Motivación de un campesino del Salvador antes de irse a los Estados.

${ }_{5}$ Testimonio de un serrano de Honduras, 2003.

${ }^{6}$ Migrante de Guatemala, 1998.

${ }^{7}$ Migrante de Perú, 1989.
} 
Una vez más la migración se pinta de misión y asume los rasgos de la respuesta a una vocación. El migrante sale para regresar a sus padres una dignidad perdida. En el subconsciente esto significa cumplir con el IV mandamiento: Honrar a tu padre y a tu madre. No se avergüenzan de la pobreza, no, porque muchos de ellos la viven todavía como bienaventuranza. Es la pobreza preñada de dolor, es el hogar y son las calles vueltas hospitales ambulantes todos los días lo que impulsan a estos Cristos de la migración volcarse al camino.

En el migrante el filo de la navaja que lleva a la ruptura entre pobreza vivida con dignidad y una pobreza ya motivo de estigma, son distintos factores. Primero es la percepción de una pobreza que ya ha rebasado el umbral entre muerte y sobrevivencia; luego el bombardeo de los medios de comunicación, de la moda, de los que regresan desde el Norte ostentando fachadas de riqueza vacía: quien ha quedado atrás se encuentra de repente como objeto de mofa, de una acusación callada que suena a derrotado y hasta a cobarde.

Hay, por un lado, la percepción de ser objeto de desprecio, de valer menos y por el otro lado un sentido e inexpresado derecho a tener y hasta ser lo que los demás ostentan. Empieza así el proceso complejo y dramático que desembocará en la decisión de partir. Hay un llamado confuso que invita a dejar una situación que ha rebasado el umbral de aguante, existe una ruptura con el ambiente y consigo mismo que clama por una superación. Se ven los ojos ausentes y cansados de las personas queridas, padres e hijos o parejas, que terminan por ser interpretados como un pedido por algo más.

«Miraba mi aldea, muñón destrozado por la guerra entre hermanos. Las milpas destruidas, la madre tierra rayada en su intimidad, desgarrada por la rabia de hermanos en guerra. ${ }^{8}$

Es cierto que la guerra civil en Centro América dejó devastación, enemistades y pobreza, sin embargo se volvió momento meditativo de valores ancestrales tales como la tierra y la hermandad entre pueblos. Esta «tierra rayada en su intimidad» es percibida por el migrante que la abandona como tener que salir del Edén, abandonar el lugar escogido por Dios a causa de un pecado que se repite. Es el mismo concepto expresado con dignidad y entre sollozos por un hondureño de la Ceiba, cuando nos decía: si tengo que morir de hambre en mi país, prefiero morir dando un paso hacia el horizonte $y$ dejar a mi espalda una patria amargada por el despilfarro de sus gobernantes. Hay en este pasaje y en otros similares el deseo inexpresado de rescatar esta madre tierra, de devolverle un día su dignidad. El éxodo aquí se vuelve otra vez una misión. Sí, no hay que renegar porque es la voluntad de Dios y si salimos llorando queremos regresar cantando.?

\footnotetext{
8 Un campesino de Tenancingo (El Salvador) después de los acuerdos de paz, 1992.

${ }^{9}$ Refugiado de Nicaragua en un campamento de Honduras, Pascua de1989.
} 
La dimensión de la voluntad de Dios en la decisión de emigrar se acompaña a lo largo de todo el itinerario del migrante, inclusive perdura cuando ya finalizó el cruce y se ha asentado en la nueva tierra. El migrante vive en el dolor la voluntad de Dios, una voluntad que nuestra lógica occidental o moderna descarga sobre la malicia de quien planea la economía o gobierna la política. El latinoamericano, desde hace tiempo, ha creado para su mundo cotidiano e histórico una relación tal vez para los filósofos virtual, y de sobra real, donde saca agua como de un pozo personal.

"Algún día volveremos a nuestra tierra, esa es la esperanza que nos mantiene vivos. ${ }^{10}$

«iLa esperanza no llena el estomago, pero nos mantiene! $»^{11}$

El migrante unifica en su vida el connubio fe-esperanza en un columpio siempre armónico. En sus relatos, de una fe ciega alimentada por una esperanza que la ilumina y la sostiene, vinen a mi mente los trapecistas danzando en el vacío. A cada rato se tiene la impresión de que se caen y siempre se enganchan con una mano que parece salir de la nada. Es una esperanza que enciende la noche, anticipa la salida del túnel, contagia las tinieblas de la noche y de cuantos ya resignados quisieran sentarse a lo largo del camino. A veces esta esperanza se vuelve una piedra que tienes que patear para seguir viéndola delante de ti. Todo parece cerrarse sobre tus sueños, las veredas se vuelven emboscadas, los retenes auténticas horcas caudinas.

\section{La despedida-sus rituales}

La despedida empieza con la última visita al campo, a la milpa, que muchas veces se tuvo que hipotecar o vender para pagar los gastos del viaje o del coyote. ${ }^{12}$ Es una mirada triste, que precede la despedida de la madre. Tierra y madre para el campesino latinoamericano guardan todavía el proyecto primigenio de la creación, en una relación de amistad hermanada.

Lo he perdido todo, padrecito, me han robado lo que traía, aquellos cuatro Colones que me dieron por aquel pedazo de tierra. Había sido el pecho que amamantaba a mis criaturas y a mi doña, pero ya se iba secando. ${ }^{13}$ Tenía ganas de llorar, enmudecido, no salían las lágrimas, pero aquella era tierra dejada por mi padre, lugar de su sudor y de su trabajo. ${ }^{14}$

\section{Estos testimonios preceden la} despedida de la madre y de su propio hogar. Se reúnen los familiares, muchas veces los vecinos: entre pobres no hay ni barreras ni desconocidos, se

${ }^{10}$ Refugiado guatemalteco en los campamentos de Tziscau, en Chiapas, 1990.

${ }^{11}$ Campesina de la zona guerrillera en Chalatenango, El Salvador.

${ }^{12}$ En la jerga de los migrantes y de la población común, así como para las autoridades migratorias el coyote o pollero es quien se contrata para llevarlo a uno a su destino a través de los retenes, de caminos de extravío y cruzando fronteras. Es un traficante de personas o contrabandista de gente.

${ }^{13}$ Migrante salvadoreño del Departamento de la Unión.

${ }^{14}$ Campesino de Nicaragua. 
comparten unos dulces, también un trago, se dan los últimos consejos.

Luego es el momento de las encomiendas para parientes, amigos que ya se fueron. A lo poco sigue la entrega de imágenes de santos, unas oraciones que pertenecieron a algún ser querido, la imposición del escapulario o de la camándula (la corona del rosario en Centro América), unas fotos chiquitas de los hijos, de la madre, de la casa; toda una pequeña serie de contactos, direcciones, teléfonos escritos en una tira de papel y cocida muchas veces en los pantalones. (Me recuerdan las litterae comunionis de las primeras comunidades cristianas, cuando se despedían de alguien que emprendía un viaje). El abrazo a los hijos, a la madre, a la esposa. Se acompaña con aspersión de agua, bendita y con la bendición en forma de cruz en la frente o sobre el pecho, si son católicos.

En esta despedida del migrante con sus oraciones espontáneas y con las que uno se lleva en el bolsillo tenemos un sacramentario sencillo, sin rúbricas y sin embargo lenguaje de su liturgia. La pequeña comunidad lo envía como el viejo Tobías al joven Tobit, acompañado por un ángel protector, Rafael, quien en nuestro caso cambia de nombre: es el ángel de la guarda, la Virgen del pueblo o del país, un santo protector taumatúrgico o encomendado por la abuelita o el cura del poblado, el Beato
Scalabriniano cuando pasan por nuestras Casas del Migrante, y muchos más.

"Me iba riendo, hasta contando chistes con unos compañeros, pero adentro la tristeza parecía una piedra, que me aplastaba sin poderla remover. No quería voltearme a ver atrás. Escuchaba los sollozos de mi madre, hasta los pájaros parecían llorar.» ${ }^{15}$

Las raíces han sido cortadas: pedazos de carne y de tierra se van para el norte. - El sudor del pobre es su llanto callado. ${ }^{16}$

La decisión de migrar penetra en el corazón del migrante y más aun del refugiado como experiencia de muerte: lo aplasta en sus raíces hasta desgarrarlo. Él sabe que tendrá que brincar una zanja, abrir un vacío entre sí mismo y quienes quedan, desaparecer al horizonte, aceptar ser tragado por un tiempo de silencio, por la incertidumbre del mañana. Al mismo tiempo quiere encadenarse a su hogar: lo hace con promesas, con un recuerdo, con besos y seguido con lágrimas.

\section{Demasiadas veces somos} espectadores del río de migrantes que pasa por nuestras fronteras, que van merodeando en nuestras plazas. Ignoramos su tragedia, la herida todavía abierta por una decisión que la mayoría quisiera no tomar nunca. Esta ruptura, donde el migrante como el Cristo se parten, tiene como destinatarios a sus familiares, las bocas de un hogar, el gemido a veces de pequeños que piden a la 
Providencia de Dios que se haga presente, que se vuelva ángel.

Todo migrante se reconoce en esta plegaria de Cristo. Pide a Dios que proteja a su familia, que los cuide, que un día puedan estar otra vez juntos. Es un puente que se estira hasta rechinar en todas sus junturas bajo la conmoción de la despedida y nada deja al azar. Es siempre una pequeña misa la que sella la despedida para el Norte: oración -abrazo de paz y comunión- la bendición final.

Cuántas veces hemos sido testigos de la fracción del pan entre los indocumentados, todos comparten lo que tienen, estrechan la mano al desconocido, levantan a quien ha caído, dan desde su pobreza. Es un sacrificio callado el de miles de migrantes, que más tarde y no siempre se vuelve memorial. Seguido de la muerte que no deja rastro; la derrota, el olvido recluyen aquel sacrificio en una fosa común, que tan solo la resurrección entregará de vuelta en cielos nuevos y tierra nueva.

\section{Vivencia en la trayectoria}

La experiencia del migrante a lo largo del camino hacia una tierra desconocida, imaginada tan sólo a través de la televisión, de las exageraciones de cuantos dicen conocerla, sin haber nunca estado allá o de los que regresan y la pintan como tierra de otro planeta, conjuga al mismo tiempo el camino de los Patriarcas y del pueblo de Dios en su éxodo por un lado y el Vía Crucis del Cristo por el otro.

Las dificultades empiezan ya doblando la primera esquina del pueblo y asumen nombres distintos, desde la nostalgia que cual mal sutil (tuberculosis) se acompaña al migrante, ${ }^{17}$ al policía paisano que quiere para su refresco, a un compañero que luego luego te dice que no trae nada y que le piches una pupusa. Luego llegan las fronteras, los buitres uniformados, la bestia, el campo minado, los verdes y los azules (las uniformes de la Migración y de la Policía) los Maras Salvatruchas y la guillotina de acero (el tren carguero). ${ }^{18}$

\section{Altares y piedras votivas}

"Manos piadosas plantaron una cruz a lo largo de los rieles, para Manuel.» ${ }^{19}$

A Manuel lo encontró su hermano a los 6 meses, en una fosa común del cementerio de Matías Romero, estado de Oaxaca. Alguien sin embargo había plantado una pequeña cruz con su

\footnotetext{
${ }^{17}$ Beato J.B. Scalabrini, 1897.

${ }^{18}$ Son los apodos de los indocumentados llegando a la frontera de México y cruzando desde Centro América: los buitres uniformados son los soldados del ejército mexicano que piden la primera mordida, la bestia es México en general con todos los obstáculos, el campo minado el sin número de retenes y chequeos que constituyen una frontera vertical que va desde el Suchiate, río que separa México de Guatemala hasta el Río Bravo, con Texas, verdes y azules son los oficiales de Migración o las policías sectorial, estatal o municipal, los Maras Salvatruchas unas pandillas despiadadas que asaltan a lo largo del camino y la guillotina de hierro el tren carguero usado por la mayoría de ellos, que ha cobrado vida o piernas o brazos.

${ }^{19}$ Manuel, del Departamento del Paraíso, Honduras, muerto arrastrado por el tren carguero en Matías Romero, Chiapas, 1999.
} 
nombre. Son lápidas de resurrección, último grito destrozado hacia un más allá, No ha muerto un animal, un hijo de nadie, como considera mucha gente al indocumentado, queda un llamado a la vida. Otros escriben el nombre o simplemente amigo-compañero sobre una piedra. He quedado conmovido delante de un montículo, que unos compañeros erigieron en la mera frontera entre Tijuana y San Diego, California, para recordar todos los muertos en ese cruce. Es un altar celebrativo, donde la naturaleza entona y libera su liturgia y canto.

Son frecuentes las señas, las flores $y$ las veladoras ofrecidas en puntos específicos, para marcar y recordar la historia, un encuentro, un peligro escapado, una acción de gracias. En las iglesias o capillas que los acogen, los migrantes quieren dejar este recuerdo. Lo quieren pagar, quieren que le cueste.

«A veces el canto de los pájaros nos parecía ser el lamento de nosotros peregrinos encadenados. $»^{20}$

Otro testimonio, que tal vez alcance una cumbre dramática por el contexto histórico y por un grupo de cristianos comprometidos, nos da el alcance de cómo la liturgia del pueblo puede expresar al mismo tiempo confianza, fe y abandono.

Mirando al vacío, como remontándose, al tiempo el más anciano empezó:
-Éramos varios grupos, católicos y evangélicos, que nos fuimos encontrando por el camino hasta llegar a ser casi ochocientas personas. Caminamos durante un mes. Sin saber por donde ni hacia donde íbamos. Había momentos en que queríamos regresar porque no teníamos que comer, algunos ancianos no lograban seguir caminando. Sin embargo seguíamos. La oración diaria, el tomarnos de la mano, el pedirle a Dios era la fuente que alimentaba nuestra esperanza. Cantábamos a veces unos salmos, pero baja voz, por miedo de ser descubiertos.

Llegamos a un punto donde la "Contra» (movimiento guerrillero contra la revolución sandinista y su gobierno) que iba por delante tuvo un enfrentamiento con las tropas sandinistas que los estaban esperando. Nosotros empezamos a leer la Palabra de Dios y a cantar mientras las hojas de los árboles caían como lluvia por los bombazos. Teníamos que salir de ahí, cruzar por en medio de los dos bandos porque si no nos matarían a todos.

Entonces sintiendo la mano poderosa del Señor que nos protegía cruzamos por en medio de los bandos.

Sentíamos que las balas nos rozaban y hacían bailar el pasto mientras arrastrándonos por el suelo o corriendo cruzábamos. Tan sólo a una mujer se le enterró una bala en el tobillo, los demás logramos cruzar sin que nos hicieran daño. Los salmos marcaban el ritmo de nuestros pasos en el peregrinar de nuestra esperanza hacia la vida y la libertad. ${ }^{21}$

\footnotetext{
${ }^{20}$ Relato de un grupo de campesinos en El Salvador huyendo de la persecución del ejército, 1986.

${ }^{21}$ Testimonio de un grupo de refugiados nicaragüenses en Guásimos, Departamento del Paraíso, Honduras, 1987.
} 
Constructores de paz

Creer en la paz, fruto de la justicia $y$ del amor es una expresión de la fe en Dios $y$ al mismo tiempo, una forma de creer en el hombre. La paz es posible. ${ }^{22}$

Una nota discriminatoria, característica en contra de los migrantes, tal vez a nivel mundial, es la de considerarlos chivos expiatorios por todo tipo de acontecimiento negativo que pase en la comunidad o en el país de acogida. Un análisis, aún superficial, de glotología de las expresiones sobre el migrante que intenta cruzar a Estados Unidos, nos muestra un camino todo en bajada. En los años del programa bracero era simplemente wet back (espalda mojada), luego se pasó a indocumentado, más tarde ya era ilegal y hoy es un posible criminal o terrorista.

El migrante busca trabajo y, menos que todo, pleitos o volver a entrar en conflictos que muchas veces deja a su espalda, sobre todo si huye de una guerra civil. Es su misma inseguridad, el miedo que constituye su segunda piel el que propicia una actitud de paz y muchas veces de sumisión.

"Tenemos dos manos que quieren trabajar, marcadas por los callos y que se volvieron como cuchillas de un arado: ว̀Por qué nos acusan de criminales o terroristas ideológicos?.»23

El migrante latinoamericano y campesino vive de forma innata la vocación de continuar prestando mano a la obra de Dios en la creación. La paz es el contexto y el marco religioso donde modela sus sueños y proyecto de vida.

\section{La tierra de todos}

La tierra se hizo para caminarla de punta a punta, para eso la hizo Dios. ¿Por qué no voy a entrar? Es el hombre quien ha puesto fronteras. La tierra es nuestra madre que da a luz, que pare; ella misma es la vida, por eso la amamos y protegemos. ${ }^{24}$

Las dos concepciones de la tierra, una como posesión, la otra como lugar del andar del ser humano y de su convivencia con los demás entran en ruta de colisión. El concepto de Madre Tierra, $\tan$ fuerte en los Indígenas de Latino América y por mi experiencia de los Altiplanos de Guatemala, no logra aceptar que se le pongan fronteras, que la Tierra sea encadenada por unos cuantos, que ya no pueda hablar el idioma de todos porque le pusieron un bozal en nombre de la soberanía nacional, de las economías regionales o de la seguridad. Es la visión cósmica de quien no pasa por la tierra como invasor, declarando la guerra a todo rival.

«ว̇Por qué nos ponen púas y perros de acero cuando queremos ofrecer dos manos para trabajar allá una tierra que Dios dio para todos y hay áreas aún abandonadas?» ${ }^{25}$

${ }^{22}$ Delegado de la Palabra del Salvador, que venía solicitando Refugio a la embajada de Canadá en México.

${ }^{23}$ Migrante hondureño de Copán, 2001.

${ }^{24}$ Migrante indocumentado de Guatemala, 1998.

${ }^{25}$ Parte de una oración de los fieles en el Caños Zapata, Tijuana, en la mera línea de división entre México y USA, durante una Eucaristía en el descampado, bajo los binoculares de la Migra (1986). 
Constatación amarga, que rebasa la simple queja o el coraje de chocar con un mundo absurdo. Es el asombro todavía inocente del campesino, que se siente enlazado por un amor filial con la madre tierra, fuente que amamanta a sus hijos y a él mismo y alguien, por otro lado, de forma absurda destroza esta relación vital. Pero hay más aún, el indocumentado está delante de una tierra cercada y militarizada, donde él no puede entrar y es rechazado como perro o criminal, se pregunta żcuál es su pecado o su culpa? Revivir la experiencia de Génesis, desterrados del Edén, desnudos y avergonzados, es como volver a una pesadilla. ¿̇Por qué? Es la pregunta sin respuesta.

Quién convirtió esta tierra en tu destierro y en tu prisión no sabe de tantos dolores, ni qué sientes, mientras tu sonrisa se va acabando sin nunca llegar al final. Esta tierra es tu paraíso y tu destierro, tu prisión y libertad tu vida... y tu muerte. Quizá algún día, de cualquier forma, en algún lugar, logremos tener la capacidad para tornar los volcanes de pólvora en montañas verdes, para sembrar hortalizas en los campos minados, para rezarle a tantas cruces, y sobre todo, para poder cargar esos niños en nuestros brazos y tomar el arado que nosotros empujábamos antes. ${ }^{26}$

Nos quitamos los zapatos, dejando que los pies se llenaran de polvo en ese caminar hacia esa tierra que nos dará pan, aunque nos hace sudar. ${ }^{27}$

El indocumentado no considera la tierra meta de su emigración como una tierra prometida, simplemente es una tierra de donde sacará pan para sí mismo y su hogar, un lugar de empleo, donde, por quizá inexplicables circunstancias, se le paga más el mismo trabajo llevado a cabo en su país. Si queremos, es una extensión de la tierra que acaba de dejar, la misma rentada por Dios a la humanidad. Si para el pueblo de Israel Egipto representaba el lugar de la esclavitud y del destierro, para el migrante la tierra que deja queda como cuna de sus raíces, el objeto de su nostalgia, donde acurruca su soledad, se refugia en la depresión y alimenta la esperanza de volver mañana con un pan menos amargo.

\section{El memorial-la celebración de un pasa- do vivido hoy}

Los testimonios de nuestros compañeros de campamento, las historias que nos contábamos, eso era lo que sostenía la esperanza de nuestro mañana, los cantos empezados allá en nuestras aldeas y nacidos a lo largo del camino nos recuerdan los salmos del destierro de Babilonia, transforman el alma en tormento de la libertad. ${ }^{28}$

La memoria, los relatos y hasta las leyendas que corren entre los indocumentados representan una vertiente, diría un parte aguas entre el memorial bíblico-litúrgico y el espejismo de El Dorado. Hay un filo

\footnotetext{
${ }^{26}$ Poema compuesto por un refugiado nicaragüense en Honduras, Teupasenti, 1987.

${ }^{27}$ Indocumentado cruzando a Estados Unidos, para que la Migra no los escuchara. (No sabían que la Border Patrol tienen sensores en el suelo).

${ }^{28}$ Palabras de unos Delegados de la Palabra desterrados por la guerra civil en Nicaragua.
} 
de navaja a veces que separa las dos dimensiones, tan sólo en apariencias contradictorias. Aquellos que primero abrieron camino, los que escriben o llaman por teléfono, en los chats de hoy día con foto digital y hasta en el idioma del nuevo país, tienen el poder de desencadenar una danza de sueños, que luego se traducen en el impulso de ponerse en marcha. Son relatos que se mezclan al dolor, que no esconden la derrota, la tentación de tirar la toalla y sin embargo terminan siempre en el encuentro con un rostro de Dios Providencia. Parece la firma de muchos migrantes aquella expresión de Abraham: iDios provee! (Gen.22,14)

Escuchando los corridos o volviéndose uno periodista, tienes la impresión de entrar en un mundo irreal, de estar oyendo boletines de guerra, de hazañas y de alegría. Hay toda una jerga entre ellos, una serie de apodos y de códigos, que te detectan como uno de ellos o al contrario como un extraño que no pasó por la misma aventura. En este caso se cierran las cortinas: puedes ser un infiltrado, un oficial de la Migra, un coyote o alguien enviado en exploración para asaltarte más adelante en el camino.

Los lugares de los retenes, las compañías de buses más confiables, la forma de pagar una mordida o de burlar los chequeos, los changarros donde no te niegan un taco, los contactos que siempre tienen nombres de batalla y nunca dan su verdadera identidad; lo anterior forma el marco de un memorial que no pretende ser litúrgico, pero sí, tiene todas las componentes para volverse celebración.

\section{La fe del migrante}

Al Sentarme con el pueblo migrante he sido contagiado por una fe que rebasa, una vez más, muchas categorías filosóficas y conceptuales y me obligan a repensar la teología de la misma fe.

iGracias a Dios estamos vivos! Es la expresión típica de muchos migrantes que sobreviven a la guerra cotidiana de las fronteras, veredas, caminos de extravío y a todo tipo de acoso. Esta fe que avienta el corazón de los sencillos hacia un Dios, más allá de los fracasos, de la lógica del mundo, todo esto viste al migrante como su segunda piel y hace de él una liturgia constante de diálogo con Dios.

«El es el único y verdadero libertador de nuestro pueblo. Su mano poderosa ha estado con nosotros y Él nos dará la victoria. ${ }^{29}$

La fe es garantía de lo que se espera (Hb.11,1): la esperanza es el gran sacramento de la fe del migrante. Él inventa los motivos de su esperanza, inventa un horizonte siempre al alcance de su mirada y de su paso y con ello alimenta su fe. Es una fe asombrosa, donde el revés se abandona, como para el ladrón teólogo, a apostar sobre un Cristo derrotado. Es la vivencia de quien espera algo y a alguien, rebasando todo tipo de resignación. Traducido en

${ }^{29}$ Refugiado nicaragüense en Honduras, Guasimos, 1989. 
palabras evangélicas de la gente: si tú 10 quieres, puedes...

«El refugiado viste el sayal del desterrado, casi leproso de nuestros días, pero el Cristo nos salva por la fe de un leproso samaritano.» ${ }^{30}$

En los encuentros y diálogos con los miles de migrantes que han cruzado mi camino en América latina, hay expresiones religiosas que irrumpen en la mente de un europeo y le imponen un alto, una reflexión entre filosófica-teológica-antropológica. Expresiones como: primeramente Dios; Si Dios quiere; Él sabe; Dios primero; es Su voluntad; por algo estoy aqui, etc. para citar tan sólo unas entre tantas, provocan una crítica analítica en todo ciudadano del así llamado primer mundo, acostumbrado a separar de forma tajante la vida social e histórica de la dimensión de fe y por ende considerar lo mismo desde la perspectiva antropológica, donde probablemente muchos la atribuyan simplemente a la ignorancia o al miedo delante del misterio o de la divinidad indefinida, hasta finiquitarla con la marca de superstición.

Confieso que esta última impresión fue la que yo recibí en mi primer impacto. Una mezcla de religiosidad popular aunada a una resignación que trata de escaparse hacia Dios delante de un destino que vive como ineluctable y trágico. Fue el caminar con el oído tendido hacia su corazón y la mente despejada de prejuicios lo que me hizo descubrir, cómo el migrante latinoamericano, hijo de su pueblo y de su cultura profundamente religiosa, vive un mundo subterráneo de religiosidad, muerta en muchas partes de Europa.

En este ámbito se impone una reflexión: ies posible una fe sin una práctica religiosa? claramente en la mayoría de los migrantes no se da, al lado de una fe ancestral, una correspondiente praxis sacramental, litúrgica o de compromiso comunitario. Sin embargo la fe del migrante es apostar sobre un Dios personal, concreto, con el Dios de Jesús Cristo. Él hace de su fe simplemente una opción fundamental y apunta a lo esencial. Canjea con Dios, si podemos expresarnos así, lo mínimo: un trabajo, pan para su hogar, su sobrevivencia. Es una fe sin adornos, encadenada como ancla sobre el abismo, colgante en el vacío entre un Dios padre-madre y sus hijos. «El refugiado es un muerto que anda sin nombre, ni tierra, pero Dios es su casa.... ${ }^{31}$

Se trata de dos mundos que proceden paralelos: el de la lógica, el mundo de los filósofos y de los matemáticos, diría Blaise Pascal, es distinto y el mundo de los sencillos, que tienen como única ancla de esperanza la gratuidad misteriosa de Dios. Él es la casa abierta en todo tiempo y lugar, es un hilo directo, una hot line entre cielo y tierra.

Mira padrecito, para mi hablar con Dios es como ir al cementerio. No te espantes: vas cuando se te da la gana, a cualquier hora del día o de la noche

${ }^{30}$ Comentario de un Delegado de la Palabra en los campamentos de Honduras, Teupasenti 1989.

${ }^{31}$ Migrante peruano de paso por Tapachula, verano 2001. 
y siempre encuentras a tus muertos, no necesitas cita, y menos aún quedarte en sala de espera. No te interrumpen, ni te dicen que tienen otra cita o que están esperando una persona más importante. Ellos no te contestan, tú dices y así te parece, pero no es cierto. Tú hablas con ellos, los escuchas y te sales con un puente renovado sobre el vacío y el silencio.

Así me pasa con mi Dios. ${ }^{32}$

Esta comparación con el cementerio me pareció al comienzo de mal sabor, exotérica y algo fría. Sin embargo tuve que reconocer una vez más que en la percepción del migrante latino americano, su religiosidad se extiende y radica más allá de la lógica y está impregnada de fe, que une su vida presente, sus antepasados que han dejado un puente de luz para indicar el camino con ese Dios del cerca y del junto ${ }^{33}$ y misterioso también. Hay un hilo directo con la divinidad, con el más allá.

«Para hablar con Dios no necesitas tarjeta telefónica: puedes hacerlo siempre por cobrar.. ${ }^{34}$

Parecen derrotados a veces, cuando llegan a nuestras Casas. Hasta la ropa se ha venido carcomiendo, la piel muestra toda su vulnerabilidad, con los hongos que se han metido desde las uñas de los pies hasta los ingles, cuando no se trata de cicatrices por asaltos tienen moretones por golpes o caídas. De instinto y por compasión les preguntamos para qué quieren seguir, mejor que se regresen. Ellos simplemente miran hacia arriba y te contestan: primeramente Dios vamos a llegar. Él puede abrir todas las puertas.

«Sin embargo no puedo ignorar o callarme otra cara de la medalla, donde el migrante o el refugiado, con tal de ganarse paso o superar su problema inmediato recurre a la trampa y al engaño.»

Es una historia de mentiras y de dolo. También el migrante recurre una que otra vez a esta estratagema para salirse de apuros, ganar un poco de compasión, mover corazones de piedra, pero luego le pide perdón a Dios.

«El de nosotros es un camino en medio de un campo minado. Mira, padrecito, allá en el Salvador, durante la guerra civil, nosotros sabíamos donde estaban los frentes. Aquí estamos rodeados por un cerco invisible, todo puede ser tu amigo o tu enemigo.. ${ }^{35}$

El migrante recurre a cualquier ardid para sobrevivir. Se siente animal acorralado, porque en este país la licencia de cacería en contra de él dura todo el año. En este contexto podemos entender las mentiras, las verdades a medias, el cambio de nombre. De todos modos para la autoridad, para su patria que lo expulsa él es un Don Nadie, es un sin rostro. Un apellido, entonces, vale el otro, una identidad se puede cambiar por otra: siempre soy un clandestino. Escuchamos aquí

\footnotetext{
${ }^{32}$ Migrante de Zacatecas, Tijuana 1988.

${ }^{33}$ Expresión de la religión náhuatl.

${ }^{34}$ Migrante indocumentado en Tijuana, B.C. 1988.

${ }^{35}$ Expresión de un ex guerrillero de Chalatenango, El Salvador, de paso por Tapachula, 1999.
} 
el latir de los salmos del destierro por ejemplo, del justo perseguido, del pobre objeto de injusticia.

«ฉ̇Qué importa saber de dónde venimos? Más vale saber a dónde vamos... $»^{36}$

Si puedo usar una expresión de los timoneles en los barcos modernos, diría que el migrante cuando sale pone el timón automático hacia el lugar que ha escogido: la despedida, el camino, los sueños y las travesías, todo apunta hacia la meta, hacia su mañana. El gesto de Hernán Cortés de quemarse los barcos a su espalda, diciendo que ya no hay regreso, puede ser el prototipo de todo migrante.

Este aspecto se me reveló hace poco en el encuentro, que se prolongó por varias semanas, con un joven nacido en el Salvador en plena guerra civil. Si historia es que a los 6 meses su madre logra escaparse y entrar a Estados Unidos, donde empieza una nueva vida. El niño crece, habla casi sólo inglés, frecuenta la escuela gringa, como él me decía, hasta que al año su madre es acribillada en circunstancias aún desconocidas. No tiene familiares, pasa de una casa a otra, hasta que un día a los 18 años cruza por Nuevo Laredo y al regresar a Texas le piden identificarse. Se le hace fácil contestar que él es americano y se descubre que no tiene papeles.

Lo deportan a México y de ahí a El Salvador, porque dice haber nacido allá, pasa seis meses como bola de ping pong; no sabe en que departamento nació, si tiene hermanos o hermanas, nunca conoció a su padre: es un huérfano de raíces e identidad. Conversando con él le mencioné que a través de Naciones Unidad se podía intentar darle una ciudadanía y con mi asombro me contesta: Who cares for a citizenship? I've to arrange my life, first.

El migrante no mide su camino por lo que lo separa de su tierra y de su pasado, sino por lo que le falta para llegar. Es una actitud de libertad, que conlleva mucho más que tan sólo un ir de viaje, un caminar. Es en el fondo la actitud de quien sigue con el pie levantado, listo para cualquier éxodo.

Vive así el mismo choque que experimenta con el idioma de la nueva tierra en que se establece. La liturgia, también allá se celebra en su propio idioma, pero no es la misma. Las palabras son difíciles, no se ponen al tanto con la jerga de los batos, se siente en aprietos, porque se encuentra delante de un lenguaje que pone distancia entre la celebración y la forma de expresarse. ${ }^{37}$

Asistimos aquí a un fenómeno extraño por parte de la iglesia y por parte también del migrante, así como de unos sectores sencillos del pueblo de Dios. En el otro frente pasa lo mismo: tradiciones populares, devociones de la religiosidad de la gente tienen raíces muy profundas y se producen resistencias, hasta violentas, cuando se quieren cambiar o modificar.

\footnotetext{
${ }^{36}$ Expresión de una muchacha de Nicaragua en el Cañón Zapata, Tijuana 1986.

${ }^{37}$ Esta observación vale también para misas con los niños o adolescentes que usan un lenguaje muy distinto, continuamente cambiante según la moda, la tecnología etc.
} 
Una razón general puede ser remitida a la incertidumbre del cambio. La otra, sobre todo en la gente sencilla se remonta, en mi opinión, a las motivaciones que han llevado a fundar y cimentar una tradición popular: la vivencia concreta y cotidiana de problemas que tan sólo la trascendencia puede resolver.

Son las respuestas a la salud, a la lluvia que riega la tierra, la fertilidad, el trabajo, el encontrar pareja entre otros y por lo general estas tradiciones se vuelven leyendas y testamentos intocables.

De repente el simbolismo y la expresividad, vividos en el camino del migrante, se apaciguan llegando a la comunidad de acogida, que ya no es migrante, aunque pueda ser compuesta por ellos. Aquí en la nueva tierra e iglesia todo está preestablecido $y$ de forma algo distinta de lo que queda atrás, no digamos de la liturgia informal del camino. El migrante en las nuevas comunidades no percibe más su lenguaje, la jerga de los batos que hablan con Dios y las respuestas de éste a otros tantos mojados.

\section{Rebasando credos y confines parroquiales}

En la aventura migratoria el católico no se aparta del evangélico, del protestante o del budista, que topa con él y se colea en el mismo río humano hacia el Norte. Esta experiencia de solidaridad, la vivencia del pertenecer a una misma familia, donde cada quien habla con un Dios que a todos escucha y acoge, termina en la comunidad de acogida. Los credos que habían convivido hasta ayer ya son muros y zanjas.

Lo mismo dígase de la parroquia, a lo largo del camino cualquier iglesia, católica o asamblea protestante pueden ser un tejaván donde orar, vivir la acogida evangélica, pedir ayuda y encontrar consuelo. Es la experiencia de una iglesia universal, donde nadie es extranjero y todos quedan invitados a la mesa de la Palabra y para nosotros del Pan partido. Llegando a una parroquia empiezan los confines para las pláticas bautismales o matrimoniales, para registrarse, horarios de oficina, horarios para confesiones, citas para platicar con un cura y muchas acciones más.

He notado, por ejemplo, cómo aquel que empieza una oración antes de la comida, o en una pausa del camino, es designado como el Delegado de la Palabra (tenemos que reconocer que los evangélicos toman más iniciativa que los católicos).

Veíamos antes cómo en el migrante no hay rebeldía o maldición por su suerte amarga. Dios sigue siendo misericordioso, el Dios de la Providencia, el Dios que nos acompaña y cobija. Es un rasgo teológico que por lo menos la pastoral tendría que tomar en cuenta, sobre todo en los sermones, donde se corre el riesgo de regresar al hoyo de donde el indocumentado había salido. El Dios del miedo o el Dios del juicio no pertenecen al mundo religioso de la migración.

Se debe hacer palanca sobre estos conceptos, ni tan viejos, que pueden alejar a quien ha salido de un Vía 
Crucis donde ha encontrado en Dios a una Verónica, a un campesino de Cirene, a unas Marías y finalmente a un Cristo que le prometió su Reino en el mismo instante en que se dirigió a Él. Hay un aforismo acuñado por los Centros de Estudio de los Scalabrinianos, que suena así: cuando la migración se mueve, las fronteras se mueven.

Es una ley socio-antropológica, donde la sociedad de acogida, aunque pueda estar en actitud discriminatoria o hasta hostil al extranjero, asume costumbres, comidas, formas de hablar o actuar que la van cambiando. Sin entrar en cuestiones de integración o enculturación social, se debe reconocer como una cita histórica de salvación este encuentro con el otro dentro de la iglesia, donde no tendríamos que tener fronteras. Una comunidad que acoge de buena o mala gana al migrante tiene que aceptar una actitud de cambio, así como el migrante tampoco puede imponer todo su mundo y pretender trasplantar lo de ayer y de allá hasta aquí y hoy. 
